\title{
Resource Delivery and Teaching in Live Chat Reference: Comparing Two Libraries
}

\author{
Paula R. Dempsey
}

This study investigates how reference staff at two libraries balance teaching with resource delivery in live chat reference. Analysis of 410 transcripts from one week shows that one library tends to deliver more resources from a wider range of database suggestions, to take more time in chat interactions, and to incorporate more teaching behavior with specific resource links. Two possible reasons for these differences are reference policies and staffing models: one library states that chat is for brief factual questions and monitors chat from a public service point; the other does not state a policy and monitors chat from private offices. Findings are important for staffing responsively, developing effective research guides, and improving teaching in online reference.

\section{Introduction}

When a student asks a librarian for help with a research assignment, will the librarian suggest a place to start looking or deliver a specific resource? Selecting a reference strategy requires balancing priorities:

- Save students' time

- Engage students in learning

- Optimize use of library collections

The imperative of teaching in reference service is established in research and professional standards, yet meeting students' immediate information needs is also vital. General approaches to reference include advising students to search the library catalog or a specific database (assuming that students can navigate to them independently) or providing a link to a research guide for the course or subject area. Delivering specific resources can mean linking to a canned search in a recommended database that incorporates the librarian's keywords and date or material type limits or sending a link to a specific journal article, book, encyclopedia article, or Web resource. In a busy chat reference service, especially one staffed at a public desk, both general and specific strategies also risk negative closure: quickly resolving an interaction without confirming whether the student's information need is satisfied. ${ }^{1}$

Because any interaction with students may be the only opportunity to work with them, librarians look for ways to package advice about collections in digestible form.

Paula R. Dempsey is Assistant Professor and Research Services E Resources Librarian in the Richard J. Daley Library at the University of Illinois at Chicago; e-mail: dempseyp@uic.edu. (C2017 Paula R. Dempsey, Attribution-NonCommercial (http://creativecommons.org/licenses/by-nc/4.0/) CC BY-NC. 
Paper pathfinders created to make students aware of relevant resources have become online research guides. Pointing to a research guide can provide a broader subject context that fosters awareness of collections. This guidance benefits not only students, but also librarians, staff, and student assistants who are less familiar with the subject.

Libraries invest substantial resources developing research guides. According to SpringShare, developer of the LibGuides platform, sites at both public and academic libraries grew from 1,023 at the end of 2009 to 4,883 at the end of April 2015. The number of guides exploded from 66,703 to 468,733 in the same period. ${ }^{2}$ Yet no research to date documents the extent to which research guides are used in virtual reference practice or their value for supporting information literacy (IL) instruction on the fly. Insights gained from analyzing the ways librarians employ online research guides in chats with students can inform reference policy, staffing models, professional development, and research guide design.

This study documents how librarians link to research guides in live chat interactions at two universities. It compares the use of research guides with more general reference strategies, such as sending a link to the library catalog, and more specific strategies, such as linking to a journal article. The analysis addressed these research questions:

- In live chat, which resource types are librarians most likely to send students in response to subject-based research questions?

- How do resource referral patterns vary by institution?

- To what extent does referral strategy affect the duration of chats?

- In what ways do librarians incorporate teaching behaviors into different linking strategies?

- What roles do research guides play in supporting live chat reference?

\section{Review of Recent Literature}

This study draws on and contributes to existing research around: 1) the role of teaching in reference service; 2) instructional strategies in virtual reference; and 3) the instructional value of research guides in academic libraries. The current study examines previous findings in light of new data and adds to the literature a focus on the resources that librarians provide. No research to date documents the types of resources librarians deliver in chat reference or the extent to which instruction accompanies resource provision. Another gap exists in understanding how librarians use research guides in everyday interactions and the extent to which guides support and extend instruction in the virtual context.

The once-active debate about whether reference services should deliver relevant resources or teach IL skills is largely settled in favor of instruction in the academic library setting. However, prominent and persuasive voices once stressed information retrieval as central to the profession's value and even survival. ${ }^{3}$ They emphasized leveraging the librarian's advanced skills to make optimal use of collections and to save students' time.

For reasons including rapid technological change and increased emphasis on accountability in higher education, academic librarianship has shifted toward recognizing each reference interaction as an opportunity for student learning. ${ }^{4}$ This perspective values engaging and empowering students for lifelong learning. Higher education library standards and behavioral guidelines assert that "Information literacy competency extends learning beyond formal classroom settings" ${ }^{5}$ and call for librarians to "provide regular instruction in a variety of contexts" 6 and to offer "pointers, detailed search paths, and names of resources used to find the answer, so that patron can learn to answer similar questions on his/her own, when appropriate."7

Near consensus on the centrality of instruction is tempered by Catherine Sheldrick Ross and Patricia Dewdney, who speculated that the focus on independent student 
learning can provide an excuse for busy librarians to terminate reference interactions without ensuring that students find relevant resources. ${ }^{8}$ In their "secret shopper" study, 44 of 100 in-person reference interactions ended in unmonitored referrals, defined as:

...when the librarian doesn't know enough about the real question or about the match between information need and recommended source(s) to have any reasonable confidence that a user who follows the advice will find an acceptable answer. ${ }^{9}$

In the real world of rapid, overlapping chats, librarians who hope to avoid unmonitored referrals may be tempted to deliver material that they believe meets the information need and move on to the next student. As Patricia E. Johnston notes,

...it is easy to just give patrons the answer, do the search for them, push those pages their way - a practice contrary to everything an academic librarian considers proper and good. ${ }^{10}$

Christina M. Desai and Stephanie J. Graves agree, stipulating that "Research should not be a magic act performed by the librarian." 11 Behaviors in the "magic act" category include the "questionable reference practices" of page pushing (sending a patron to a web page without explanation) and citation pushing (giving a citation or call number without explanation). ${ }^{12}$ Susan Avery and David Ward also documented librarians giving a starting point without monitoring its value and linking to specific search results without instruction. ${ }^{13}$

Thus we have broad consensus that student learning is an important goal of reference interactions. However, measuring learning outcomes in brief, usually anonymous, interactions is difficult, if not impossible. Therefore, researchers have focused on librarian teaching behaviors. A review of research in chat reference found that:

Chat users frequently ask for or are open to library instruction via chat, and librarians employ several techniques in providing instruction, such as suggesting resources or terms, explaining how to use resources, or modeling step-by-step approaches to searching for information. ${ }^{14}$

Table 1 shows that, in previous studies of chat reference, between 50 and 86 percent of transcripts included at least one instructional strategy.

\begin{tabular}{|l|c|c|c|}
\hline \multicolumn{4}{|c|}{ TABLE 1 } \\
Percentage of Chat Transcripts Including Any Teaching Behavior Found in \\
Current and Previous Studies \\
\hline \multicolumn{1}{|c|}{ Study } & Libraries & Sample Size & \% of Transcripts \\
\hline Current study & UL1 & $\mathrm{n}=79$ & $95 \%$ \\
\hline Moyo 2006 & 1 & $\mathrm{n}=405$ & $86 \%$ \\
\hline Desai \& Graves 2008 & 1 & $\mathrm{n}=169$ & $82 \%$ \\
\hline Current study & UL2 & $\mathrm{n}=45$ & $80 \%$ \\
\hline Zhuo 2006 & 1 & $\mathrm{n}=100$ & $67 \%$ \\
\hline Oakleaf \& VanScoy 2010 & 1 & $\mathrm{n}=1,474$ & $62 \%$ \\
\hline Johnston 2003 & 1 & $\mathrm{n}=50$ & $60 \%$ \\
\hline Platt \& Benson 2010 & 20 & $\mathrm{n}=20$ & $50 \%$ \\
\hline
\end{tabular}


Avery and Ward examined opportunities for teaching in chat interactions related to the Association of College \& Research Libraries (ACRL) Information Literacy Competency Standards for Higher Education. Teachable moments for Standard Two (Access) included "anything related to describing and implementing a search strategy to retrieving information via a variety of search tools." 15 Johnston developed a list of teaching behaviors that Lesley Moyo also adopted. Both studies documented librarians recommending databases and helping to navigate the website by modeling the search (explaining to users the steps as they go) and leading (directing users step by step on how to conduct the search on their own). ${ }^{16}$ Megan Oakleaf and Amy VanScoy reported that librarians explained their search strategy ("Think aloud"), modeled searches ("Show, don't tell"), and coached students doing the search ("Let them drive"). They found that, in 45 percent of the transcripts, a librarian pushed a page or sent a

\begin{tabular}{|c|c|c|c|c|c|}
\hline \multicolumn{6}{|c|}{$\begin{array}{c}\text { TABLE } 2 \\
\text { Teaching Behavior Relevant to Providing Resource Links }\end{array}$} \\
\hline & \multicolumn{5}{|c|}{ Study } \\
\hline & $\begin{array}{l}\text { Johnston } 2003 \\
\text { Moyo } 2006\end{array}$ & $\begin{array}{c}\text { RUSA } \\
\text { Behavioral } \\
\text { Guidelines } \\
\text { (Zhuo } \\
\text { 2006, Platt } \\
\text { \& Benson } \\
\text { 2010) }\end{array}$ & $\begin{array}{c}\text { Desai and } \\
\text { Graves } \\
2008\end{array}$ & $\begin{array}{c}\text { ACRL } \\
\text { Standard } \\
\text { Two (Avery } \\
\text { \& Ward } \\
\text { 2008) }\end{array}$ & $\begin{array}{c}\text { Oakleaf \& } \\
\text { Van Scoy } \\
2010\end{array}$ \\
\hline $\begin{array}{l}\text { 1. Search } \\
\text { Strategy }\end{array}$ & & $\begin{array}{l}\text { " } 4.1 .3 \\
\text { Explains } \\
\text { the search } \\
\text { strategy to } \\
\text { the patron." }\end{array}$ & & $\begin{array}{l}\text { "Overall } \\
\text { search } \\
\text { strategy is } \\
\text { articulated to } \\
\text { user..." }\end{array}$ & $\begin{array}{l}\text { "Think } \\
\text { aloud" }\end{array}$ \\
\hline $\begin{array}{l}\text { 2. Recommending } \\
\text { Resources }\end{array}$ & $\begin{array}{l}\text { "Recommending } \\
\text { specific } \\
\text { databases to } \\
\text { be used, and } \\
\text { explaining the } \\
\text { reason for the } \\
\text { selection" }\end{array}$ & $\begin{array}{l}\text { "4.1.2 } \\
\text { Identifies } \\
\text { appropriate } \\
\text { sources } \\
\text { that are } \\
\text { most likely } \\
\text { to contain } \\
\text { information } \\
\text { relevant to } \\
\text { the patron's } \\
\text { query." }\end{array}$ & $\begin{array}{l}\text { Resource } \\
\text { Suggestion }\end{array}$ & $\begin{array}{l}\text { “...what } \\
\text { types of } \\
\text { information } \\
\text { are } \\
\text { contained in } \\
\text { the selected } \\
\text { resource" }\end{array}$ & \\
\hline 3. Keywords & & & & $\begin{array}{l}\text { "...which } \\
\text { search terms } \\
\text { will be } \\
\text { used..." }\end{array}$ & \\
\hline 4. Navigation & $\begin{array}{l}\text { "Guiding } \\
\text { patrons in } \\
\text { navigating the } \\
\text { library's web } \\
\text { resources" }\end{array}$ & $\begin{array}{l}\text { "4.1.7 } \\
\text { Explains } \\
\text { how to use } \\
\text { sources } \\
\text { when } \\
\text { appropriate." }\end{array}$ & $\begin{array}{l}\text { Modeling } \\
\text { Leading }\end{array}$ & $\begin{array}{l}\text { "User is } \\
\text { guided to an } \\
\text { appropriate } \\
\text { resource for } \\
\text { accessing } \\
\text { information" }\end{array}$ & $\begin{array}{l}\text { "Show, } \\
\text { don't tell" } \\
\text { "Let them } \\
\text { drive" }\end{array}$ \\
\hline
\end{tabular}


URL, but only 15 percent of the transcripts included a librarian coaching the student through the steps. ${ }^{17}$ The current study defines "modeling" as the librarian explaining each search step while doing it. "Coaching" refers to the librarian telling the student what to do step by step.

Table 2 shows the teaching behaviors assessed in previous research that are most relevant to delivering information:

1. Search strategy: Thinking aloud about the ways(s) to find needed resources.

2. Recommending resources: Suggesting places to search (such as library databases).

3. Keywords: Providing search terms and/or encouraging the student to generate options while discussing the topic.

4. Navigation: Modeling a successful search or coaching the student through the steps.

Taken as a set, these strategies avoid both unmonitored referrals (providing a starting point without follow-up) and magic acts (providing resource links without instruction).

Teaching takes time. Librarians have looked for ways to distill key lessons into written form to save time when the service point is busy. Susan E. Beck and Nancy B. Turner advocated using paper handouts at the desk - not to replace reference service, but as "an equal partner in teaching library use." 18 Research guide design ranges from "pathfinder" lists of resources to process-focused tutorial formats. ${ }^{19}$ Studies have identified instructional elements in guides for forestry, ${ }^{20}$ political science, ${ }^{21}$ international business law, ${ }^{22}$ health sciences, ${ }^{23}$ and psychology. ${ }^{24}$ Mira Foster et al. found that instruction is an effective way to promote the use of research guides. ${ }^{25}$ Ryan Rafferty found that research guides are effective in promoting library resources. ${ }^{26}$ Questions persist about how research guides contribute to student learning, but researchers are beginning to investigate their potential for self-guided instruction. ${ }^{27}$ No study documents the role of research guides in unmonitored referrals, the virtual equivalent of pointing to the reference stacks for a call number range. The present study addresses this gap by comparing how librarians from two universities use research guides and other resource links.

\section{Data and Methods}

This research examined 410 transcripts generated by one week's chat reference service at two academic libraries: 265 from University Library 1 (UL1) and 165 from University Library 2 (UL2). The labels UL1 and UL2 protect the staff's anonymity, a stipulation of institutional review board (IRB) determinations that this is not human subjects research. The sample comprises interactions from a week in Fall 2013, soon after midterm exams, when students were likely to be engaged in substantive research. The purposive sampling strategy is not to generalize to all chat interactions, but rather to focus on subject research questions. Findings are most applicable to high-demand periods at institutions with many remote or commuter students.

UL1 serves a large, private, doctoral-level institution with multiple campuses and 90 percent commuter students. UL2 serves a smaller, public institution with 100 percent commuter students. UL1 has nearly six times more resources in its A-Z databases list (not all paid resources) than UL2. However, a previous study of these transcripts with different research questions documented roughly equivalent library spending and staffing levels per student. ${ }^{28}$

At the time the transcripts were gathered, both libraries monitored live chat during all hours the library was open. Roughly 25 percent of all questions received by each library came via live chat. Differing service policies and work settings provide a useful comparison. A user-facing service policy at UL2 stated, "Chat and text messaging should be used for brief, factual questions"; UL1 did not state a service scope. UL1 
librarians monitored chat from private offices until 5:00 p.m. and from a public desk after 5:00 p.m. and on weekends. UL2 librarians worked from a public desk where they also responded to telephone and walk-up inquiries. As the analysis will show, the service policy did not influence what questions UL2 students asked, but its underlying assumptions about student needs and behavior might have influenced the staffing model. Many other institutional and librarian-specific variables potentially influence the amount and effectiveness of teaching behaviors in chat reference service; they are addressed below in directions for further research.

The qualitative analysis relied on NVivo software, which stores and organizes data and allows multiple levels of coding. Codes for this project were not thematic, but rather interaction-oriented: what happened in each turn at chat, and how did the other participant respond? Coding proceeded in five stages. After each stage, the passages with that code were reviewed systematically to confirm consistency, an approach known as constant comparison. ${ }^{29}$

1. What kind of question did the patron ask? $?^{30}$

2. To what resource did the librarian refer the student-a research guide, a database, a canned search strategy, or a specific journal article, book, online encyclopedia article, or other resource? ${ }^{31}$

3. Did the librarian attempt to teach research skills? This included teaching behaviors shown in table 2 and also explaining how and why to use research guides and how to limit search results.

4. Did the librarian recommend that the student come into the library for assistance or contact a specific librarian by phone or e-mail?

5. Did the librarian fail to confirm whether the resource provided was relevant and/ or sufficient for the information need (unmonitored referral)?

Finally, the duration of each interaction was calculated using time stamps included in the transcripts, deducting gaps where either the student or the librarian did not respond for longer than one minute. The duration is not precise but does reliably indicate relative duration. The comparative analysis provides numbers of transcripts in various categories to illustrate and compare service patterns, without making statistical claims inappropriate for a purposive rather than random sample.

\section{Findings}

The largest group of questions for the week at each library was the group of subjectbased research questions. The student asked for help identifying resources on a broad subject, specific topic, or assignment in 54 percent of UL1 reference questions and 58 percent of UL2 reference questions. This proportion reflects the sampling strategy -a week when students were most likely to be working on research assignments. There were also many inquiries about how to find a specific article, book, or other resource (UL1, 43\%; UL2, 35\%). Fewer questions concerned how to find a type of material, such as newspapers, films, or primary resources (UL1, 3\%; UL2, 7\%). Table 3 shows that the distribution of reference question types was roughly the same at the two libraries. Students asked more substantive research questions at UL2, even though the library's chat policy allowed only brief, factual questions. No student at either library asked a

\begin{tabular}{|l|c|c|c|}
\hline \multicolumn{4}{|c|}{ TABLE 3} \\
\hline \multicolumn{4}{|c|}{ Types of Reference Inquiries by Library (UL1 n = 146, UL2 n = 77) } \\
\hline UL1 & Research (Subject or Topic) & Known Item & Material Type \\
\hline UL2 & $54 \%$ & $43 \%$ & $3 \%$ \\
\hline
\end{tabular}


factual question in the sample week, and no UL2 librarian informed a student with a subject research question about the policy. Transcript excerpts in appendix A show the range of complexity and subject matter that librarians encountered in a week's work.

To focus on research guides and other resource referrals, the rest of the analysis focused on 124 subject-based research interactions (UL1 $n=79$, UL2 $n=45$ ). Table 4 shows that research interactions at UL1 were substantially longer than those at UL2. UL1 librarians were more likely to conduct a reference interview (however minimal) and engage in instruction and far less likely to provide an unmonitored resource referral (UL1, 36\%; UL2, 74\%). UL1 and UL2 librarians frequently linked to research guides (UL1, 44\%; UL2, 40\%) and rarely referred students to other reference modes (walk-up, phone, or an appointment with a specialist) (UL1, 15\%; UL2, 13\%).

\begin{tabular}{|l|c|c|c|c|c|c|}
\hline \multicolumn{7}{|c|}{$\begin{array}{c}\text { TABLE 4 } \\
\text { Summary Data on Research Subject Interactions by Library } \\
\text { (UL1 n = 79, UL2 n = 45) }\end{array}$} \\
\hline & $\begin{array}{c}\text { Average } \\
\text { Duration } \\
\text { (Minutes) }\end{array}$ & $\begin{array}{c}\text { Reference } \\
\text { Interview }\end{array}$ & Instruction & $\begin{array}{c}\text { Research } \\
\text { Guide } \\
\text { Provided }\end{array}$ & $\begin{array}{c}\text { Unmonitored } \\
\text { Referrals }\end{array}$ & $\begin{array}{c}\text { Referral } \\
\text { Outside } \\
\text { Chat }\end{array}$ \\
\hline UL1 & 20.9 & $72 \%$ & $95 \%$ & $44 \%$ & $36 \%$ & $15 \%$ \\
\hline UL2 & 11.4 & $53 \%$ & $80 \%$ & $40 \%$ & $74 \%$ & $13 \%$ \\
\hline
\end{tabular}

Although librarians at each university had similar rates of using research guides, patterns of resource referral varied. Figure 1 shows differences between the two libraries in the types of resource links offered to students, with general "starting point" options at the top of the chart and specific "end point" options at the bottom. UL1 referral strategies tended to the specific (42\% general, $59 \%$ specific), and UL2 to the general (67\% general, 33\% specific). For example, UL1 librarians provided additional, specific resources along with a research guide ("Guide plus") as often as they provided only a research guide. In contrast, UL2 librarians offered only a guide twice as often as they included more specific resources. Other indicators that UL2 librarians provided fewer specific resources included being far more likely to provide no link of any kind (UL1, 15\%; UL2, 27\%) and far less likely to deliver a canned search link (UL1, 29\%, UL2, 13\%). UL1 and UL2 linked only to specific articles or books at roughly the same rate (UL1, 8\%; UL2, 7\%). UL1 librarians linked only to a database 5 percent of the time, less than half as often as UL2 at 13 percent. Moreover, UL1 librarians provided a far wider range of specific database suggestions (50 different databases in 79 transcripts) than did UL2 (13 databases in 45 transcripts) (see appen$\operatorname{dix} B$ ). The substantial difference in the number of databases available at each library most likely played a role here.

Figure 2 shows how linking options corresponded to the duration of chats. For each library, linking to a research guide plus more specific resources took the most time (UL1, 35 minutes; UL2, 20 minutes): 67 percent longer than average at UL1 and 82 percent longer than average at UL2. Other approaches took less time: 10-48 percent briefer than the UL1 average. At UL2, results were more mixed. UL2 librarians took more time than average providing database links (27\% longer) and canned search links ( $9 \%$ longer) and less time providing no links (36\% briefer) and article/book links ( $18 \%$ briefer). UL2 transcripts providing only a guide were of average duration.

The finding that interactions at both UL1 and UL2 were substantially longer when librarians provided both general and specific links substantiates the common percep- 


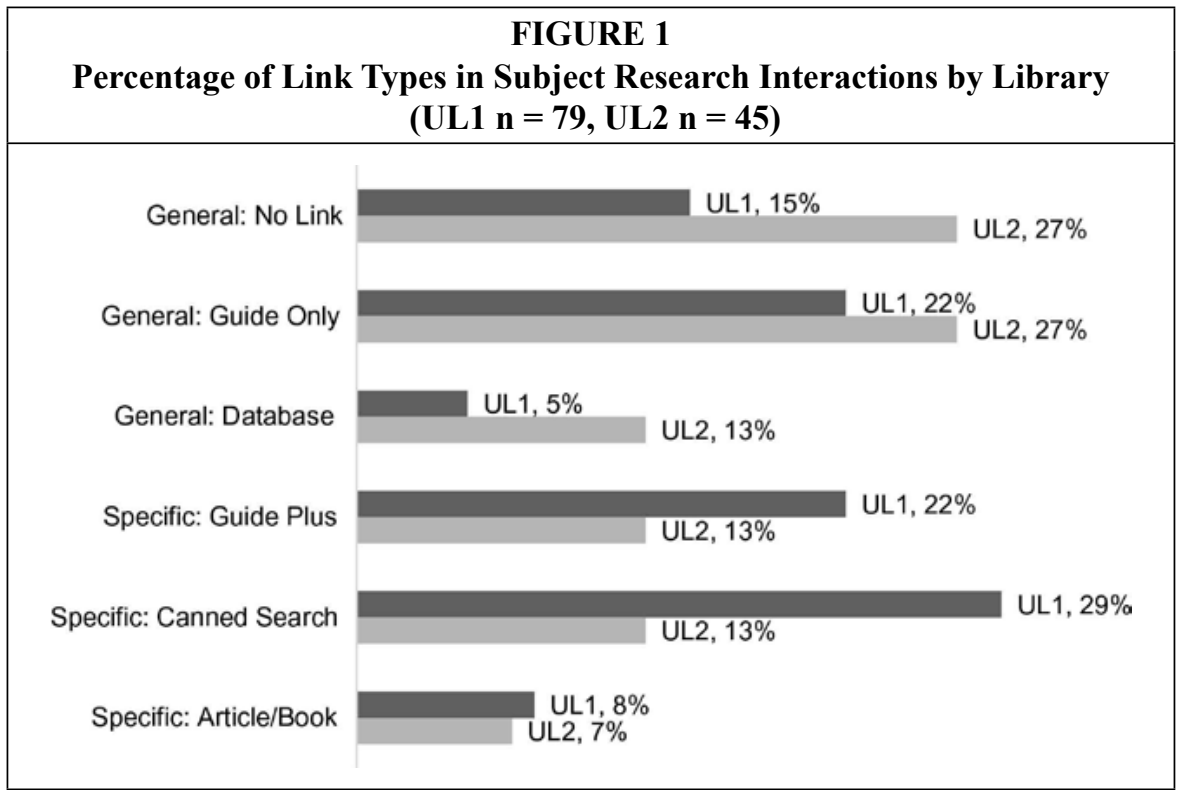

tion that teaching takes longer than delivering resources. It takes time to walk students through the research process and ensure that they find useful resources. Providing no links or only specific article/book links may be briefer at both libraries because these strategies can represent negative closure: unmonitored referrals and magic acts. Why do UL2 librarians then spend more time than average providing database and canned search links? One possible explanation is that UL2 librarians are less adept at retrieving such links because they do so less often. Analysis of teaching behaviors provides empirical support for this exploratory hypothesis.

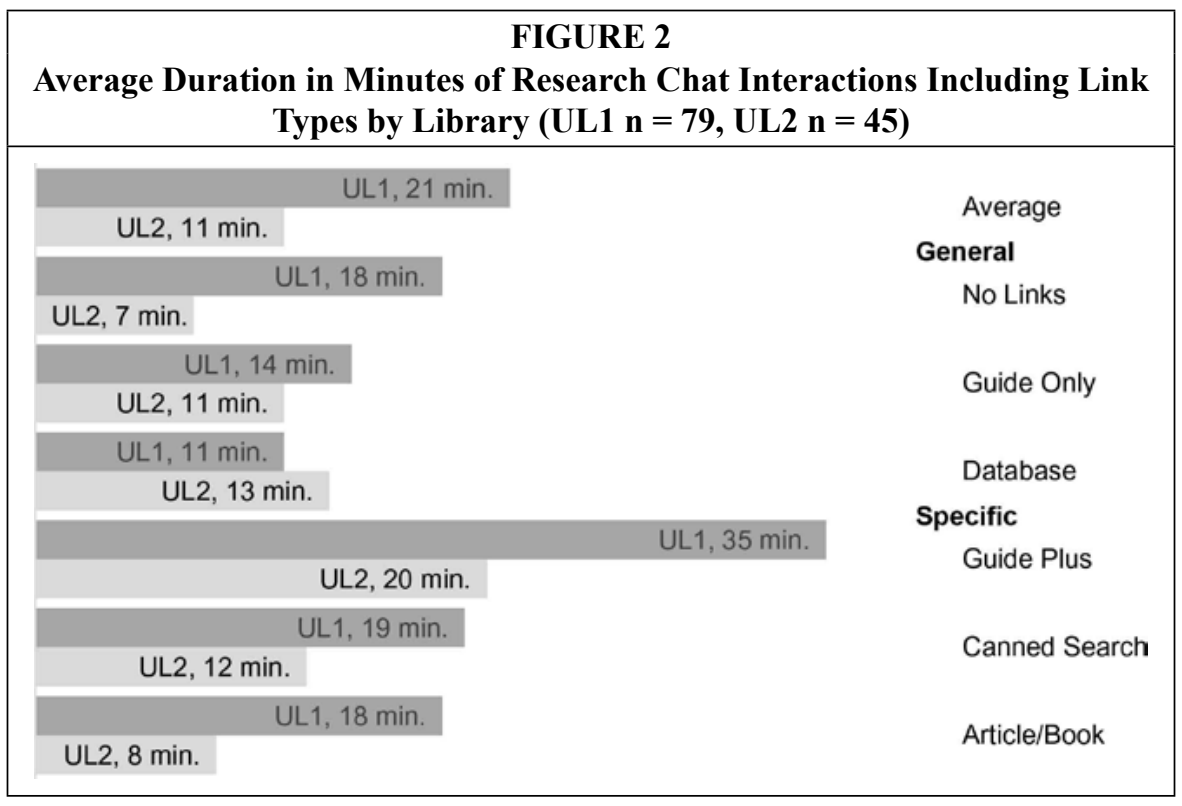


Teaching behaviors included suggesting a search strategy, recommending a database, providing keyword advice, suggesting appropriate limits, modeling the search process, or coaching a student through the search. Teaching about the research guides was uncommon. At both UL1 and UL2, librarians explained what a research guide was or how to use it less than half the time they sent students a link to one. And only two transcripts mentioned that a subject specialist in the library developed the guide:

We have some Research Guides prepared by librarians who specialize in different subjects. They have tips for getting started as well as suggestions for good databases to find articles in those particular subjects. (UL2)

I'm the Geography librarian, and do have [a recommended resource] under my guide. (UL1)

When instruction about using the guide was provided, it was often vague:

First, you can start off searching in this government research guide. (UL1) Just go to the research guides and search by subject. (UL1)

Students might not understand that the next step is to select a database rather than entering the search terms in the research guide interface.

Figure 3 shows the rate of teaching behaviors at the two libraries that accompany providing general resources (no links, a link to a research guide, or a link to a database) and specific resources (a link to a research guide plus more specific items, a canned search, or a link to a specific article or book). The graph shows that UL1 transcripts

\begin{tabular}{l} 
Teaching Behaviors Associated with General* and Specific** Resource \\
\begin{tabular}{l}
\hline \multicolumn{3}{|c|}{ FIGURE 3 } \\
Referrals by Library as a Percentage of Transcripts (UL1 n = 79, UL2 n = 45)
\end{tabular} \\
\hline
\end{tabular}


with both general and specific links usually included at least one teaching behavior (general, 94\%; specific, 95\%). However, UL1 librarians teach more intensively when providing specific links: 77 percent of UL1 transcripts with a specific link show two or more teaching behaviors, as compared with 58 percent of transcripts that provide only general links. In contrast, UL2 librarians do more teaching when providing general links: 85 percent of UL2 transcripts with a general resource link included at least one teaching behavior, compared with 66 percent of UL2 transcripts with a specific resource link. UL2 librarians also teach slightly more intensively around general links: 39 percent of general links show two or more teaching behaviors compared with 33 percent of specific links. These findings support the tentative conclusion above about differences in duration. Teaching takes longer than simply delivering links. Although not definitively proved with these data, it is reasonable to conclude that librarians who frequently deliver canned search links learn to do so more quickly.

With this pattern in mind, it is time to turn to the details of interactions at the two libraries, starting with examples of librarians providing research guides only. In transcript 1, the UL1 librarian recommended a research guide for a general topic but did not engage the student in a reference interview to find out what the student understood by "rich case study." The librarian pointed the student to a specific tab on the research guide but did not explain what a database is or give tips about limiting the search. The guide did not include instruction about how to find a case study. In transcript 2, the librarian provided links to two research guides and a quick tip about navigating the guides' tabs to find articles. The student returned after two minutes to politely request more guidance and received no answer. The particular guides sent to this student had only five or six database options, but even so the student was not clear where to start. These exchanges are far briefer than the average chat duration for each institution. The librarians provided a general starting point, but they did not attempt to discover the underlying research need. This amounts to unmonitored referral - the virtual equivalent of pointing toward the reference stacks.

Transcript 3 illustrates how research guides accompanied with more specific links can be embedded in efforts to teach IL. The librarian points out the research guide as a first step - "I'll begin by" - and models a search strategy. At time stamp 17:45, the librarian anticipates the student's question about appropriate search terms and goes on to explain how to limit by date and document type. The student returns after more than 20 minutes to report success in finding useful resources, and the librarian reinforces persistence and flexibility as dispositions of skilled searchers. The librarian not only incorporates the four teaching behaviors in table 2 but also echoes "Research as Inquiry" from the ACRL Framework for Information Literacy for Higher Education: "value persistence, adaptability, and flexibility and recognize that ambiguity can benefit the research process." 32 There is no way to assess whether the student achieved specific learning outcomes, but asking a new question of the same librarian suggests that the student benefited from the interaction.

\section{Discussion}

This comparative study shows that rates of teaching behaviors in live chat vary by library with respect to the types of resource links provided. Previous, single-institution studies found that librarians provide instruction in 50 to 86 percent of chat reference interactions. No previous study also examined what kinds of resources librarians employed in answering questions. As noted, UL1 librarians tended to offer more specific resources, whereas UL2 librarians more often provided general links as starting points. UL1 librarians also taught more when providing specific links, whereas UL2 librarians taught more when providing general links. 
What could explain why UL1 librarians were more likely to incorporate teaching when providing specific links, whereas UL2 librarians taught more when providing general links? The different staffing models, based on assumptions about student needs and behavior, might point to an explanation. The UL2 chat policy stipulated that chat is for brief, factual questions. Students did not actually limit their questions, and librarians did not enforce the policy, but the assumption of brief questions might underlie the decision to staff the service at a public desk. There was no chat policy stated at UL1, and UL1 librarians staffed the service in private offices with fewer distractions. They had the time to walk students through a complete search process (for example, starting with a research guide and ending with specific resource suggestions). UL2 librarians faced more distraction in their public work setting. The expectation that chats will be short might lead to librarians responding to in-depth research questions with general starting points, rather than guiding students through the research process. Even librarians who embrace the standards and guidelines calling for instruction might find it difficult when simultaneously fielding questions in person and by phone. However, when especially pressed for time, UL2 librarians might fall back on sending specific links to resolve the interaction sooner. In contrast, UL1 librarians who are overwhelmed might rely on general links such as research guides to resolve chats quickly.

Librarians in these data used research guides primarily as a means of pointing students to relevant databases. This is an efficient way to lead the student to a range of options for the search. However, building instructional components into research guides would allow busy librarians also to focus on IL skills, because librarians used guides as a way to occupy the student while the librarian investigated a more specific search strategy. For librarians without expertise in a subject, library student workers, and other support staff, research guides are especially important after hours when there is no colleague available to consult. If staff monitoring the chat service hit a dead end, they can refer students to contact information for the subject specialist who developed the guide.

However, librarians in these data sets often used both general and specific resource links in less than optimal ways. They sent research guides without explaining how to use them or ensuring that the student would find relevant resources (unmonitored referrals). And they delivered specific resources without reference interviews or instruction (magic acts). It is vital to ensure students find value in library collections at the same time they are becoming information literate. If librarians develop research guides with IL in mind, directing a student to a guide can be both efficient and instructional as part of modeling a search. Unfortunately, the prevailing research guide design is to list resources by format. ${ }^{33}$

Those who embrace the educational role may disparage providing specific links as spoon-feeding. The current study rejects an all-or-nothing stance. Instruction is important, and so is demonstrating professional skills and getting relevant materials into students' hands. When virtual reference traffic is high or student interest is low, a direct URL to a relevant item may serve positive purposes of demonstrating both the value of collections and of librarians' skills. Commitment to student learning does not undermine the value of delivering resources. When students request help finding resources, librarians must demonstrate their IL skills to give students the incentive to adopt their suggestions.

This study is in service of professionals reflecting on practice. In the unpredictable flow of chat, the ideal interaction is nearly impossible. How can these findings help librarians to bring practice closer to the ideal? First, the work that goes into creating research guides calls for using them effectively in the virtual context. Librarians might engage students in using research guides rather than risking negative closure by using any of the following tactics: 
- Guiding the student to the relevant section (for example: "do you see the Articles tab?").

- Pointing out specific databases for the topic rather than telling students to "search the research guide."

- Sending a link to a sample search in a suggested database to show students that it includes relevant resources.

- Mentioning that a subject specialist in the library created the guide and is available for follow-up.

Second, in designing and promoting research guides, it is important to recognize front-line virtual reference staff as stakeholders, especially student workers, paraprofessionals, and nonspecialists. Reviewing transcripts and surveying staff can reveal recurrent questions suitable for discipline-specific instructional modules (for instance, how to find psychology case studies, curriculum guides, or legal cases) to incorporate in research guides.

\section{Limitations and Directions for Further Research}

A few issues limited the analysis of these transcripts. First, keeping the transcripts anonymous prevented analysis by staff level. It is reasonable to suppose that professional librarians, paraprofessional staff, and student employees vary in their approaches to teaching and resource provision, but the identity of the person responding to the question was not available. Second, applying codes for question type and teaching behavior involved subjective judgment by an individual researcher. However, the analysis is grounded in previous research, and the data presented should allow readers to compare their own interpretations. Third, the current study considered only two of a multitude of institutional variables: user-facing policies (which question types the library considers appropriate for chat), and staffing patterns (chat monitored on or off a public desk). Further comparative research is needed to understand the impact of other variables on teaching behavior and provision of resources:

- Library standards for chat service, both official/explicit and unofficial/tacitly held

- Modes and extent of chat reference training

- Availability of subject specialists for referral of in-depth questions

- Availability of online IL instructional modules

- Proportion of students at a distance from campus

- Availability of co-browsing or screen sharing in chat platform

- Number and quality of canned messages with instructional content

Researchers can enable cross-institutional research of this kind by collaborating on studies or sharing data sets in qualitative archives. ${ }^{34}$ Some of these variables would require IRB approval of less stringent anonymity of transcripts.

There is also much still to learn about how research guides contribute to student learning and how they can best be employed in the virtual context. Investigators could profitably analyze whether adding instructional components allows reference librarians to save time in chat interactions for skills they teach frequently. Studies might examine opportunities for embedding more holistic, student-centered teaching such as the ACRL Framework in research guides. Finally, the struggle continues to measure learning outcomes in virtual reference. One possible approach is through follow-up surveys after chat interactions to assess whether students tried the strategies suggested and found the resources they needed. 


\section{TRANSCRIPT 1}

\section{Unmonitored Referral to Research Guide (UL1)}

22:09 [Student] Hi, i'm looking for a rich case study on schizophrenia and i was wondering what database would be the most resourceful.

22:10 [Librarian] Hi there!

22:10 [Librarian] Have you tried looking at the psychology research guide?

22:10 [Librarian] It can be found here: [URL]

22:11 [Librarian] Then if you click "articles", it will direct you to a list of databases you may find helpful!

22:12 [Student] Ok thanks, i will try this.

22:12 [Librarian] wonderful. let me know if you have any more questions

\section{TRANSCRIPT 2}

\section{Unmonitored Referral to Research Guide (UL2)}

15:05 [Student] Hi. Can you please help me find books and or articles that explain how the Social aspect of [neighborhood] has changed. By social, I mean nightlife, community, food and culture. If this helps, this is for a sociology course.

15:05 [Librarian] I sure can.

15:06 [Student] Thanks.

15:06 [Librarian] I would try the research guide for [City] and Sociology.

15:06 [Librarian] [URL]

15:07 [Librarian] [URL]

15:07 [Librarian] Both will have an "Articles" tab that will have the databases you will want to use.

15:07 [Student] Ok

15:09 [Student] To obtain the best results, which one do you suggest I go with for starters?

\section{TRANSCRIPT 3}

\section{Research Guide as Starting Point (UL1)}

17:36 [Student] hello

17:36 [Student] my name is [student]

17:36 [Librarian] hello [student]

17:36 [Student] an adult student who is having a hard time writing her analytical paper 17:36 [Librarian] ok

17:37 [Student] I need to write on Leadership. I need to explore servant leadership

17:37 [Librarian] what did you need help with specifically

17:37 [Librarian] and what type of resources are you trying to locate

17:37 [Student] and explore leadership across the globe

17:38 [Librarian] are you looking for articles

17:38 [Student] probably would be the best

17:38 [Librarian] and are you required to locate scholarly articles

17:39 [Librarian] one additional question - are you looking at servant leadership in a particular sector, such as business or education

17:40 [Student] I need to anylyze its effectiveness in various circumstances, environments, stuations and provide examples

17:41 [Librarian] ok

17:41 [Librarian] I'll begin by giving you a link to the management research guide

17:41 [student] okay

17:41 [Librarian] [URL, management research guide] 
17:42 [Librarian] the first database listed on this page of the guide will be a good starting point-Business Source Complete

17:44 [Librarian] this link will take you to a beginning search

17:44 [Librarian] [URL, canned search]

17:44 [Librarian] I'll list the steps I took in Business Source Complete:

17:45 [Librarian] 1. I entered servant leadership in the first search box, and I selected the SU Subject Terms field to the right of this box

17:45 [student] what key words to I start to search with. Just servant leadership

17:45 [Librarian] 2. I entered Case Stud ${ }^{*}$ in the second box, and I selected the TI Title field to the right of this box

17:46 [Librarian] did you see the link to the search I just sent you

17:46 [student] oh okay

17:46 [Librarian] these are the steps I took for this search

17:46 [Librarian] 1.

17:46 [Librarian] 1. I entered servant leadership in the first search box, and I selected the SU Subject Terms field to the right of this box

17:47 [Librarian] 2. I entered Case Stud ${ }^{*}$ in the second box, and I selected the TI Title field to the right of this box

17:47 [Librarian] I also limited by date in the left margin after I retrieved a list of results 1998-2013

17:47 [Librarian] case studies may be good sources of the different types of information you need to find about servant leadership

17:58 [student] I only got two articles

17:59 [Librarian] click through this link-I retrieved 12

17:59 [Librarian] [URL, canned search]

18:05 [Librarian] and this second link will take you to another search in Business Source Complete

18:05 [Librarian] [URL, canned search]

18:27 [student] I found some good sources

18:27 [Librarian] great-it takes time and trying different combinations of search terms [Student asks a new question; rest of transcript omitted] 


\section{APPENDIX A. Text of Subject-Based Research Questions}

\section{University Library 1}

I'm trying to find articles related to learning English as a second language / ok, so I also need to research for a fitness class... my topic is running for weight loss... thoughts on how I can search?

Hi. I am trying to find information on the influence of the Berber language on the Iberian Peninsula

I am having trouble finding sources for a paper about gmo's

hello there - I am trying to find information on the geology of the street [name] (inbetween [campus building] and the [campus building].. that whole block). I was told to look on a Geology database, but don't seem to be able to find anything. I was wondering if you could point me in the right direction?

Hi there! I am looking for some help in collecting information on teenage marriages in Albania-hopefully focusing on the seduction of outward migration, but honestly, any information is helpful. I have only been successful in gathering a few statistics and policy implications from the UN and INSTAT.

Hello! I am writing a comparative essay on homeschooling versus public school education. Here is where I am currently in my search but am not getting the results I am looking for. [URL search of ERIC for (homeschooling AND advantages) AND (public schools AND advantages)] / Can you suggest different search engine techniques?

hi i need help finding articles on the history of child abuse

Expert witness testimony in criminal trials about the credibility of eyewitness testimony- Also any info on wrongful convictions would be good too

hi i need help findind articles on child abuse but from a sociological perspective

I am looking for articles on the disadvantages of home schooling. Currently, I am here: [URL, Education Research Complete search, (SU (Home schooling)) AND (disadvantages)] / But I am not finding seeing any articles of substance, I guess. / I need an article that opposes home schooling and explains the disadvantages of this particular method of educating children.

Hi im doing a paper on the prophet Jeremiah (7:1-7) and I was wondering how I can find more articles that explain this passage/ who exactly he was and did during the time he wrote his books thanks!

hi i am writing a paper on the prophet Jeremiah and I was wondering if $\mathrm{i}$ can get some help trying to find articles on his life/ his doings. I talked to someone earlier and they told me to search on JSTOR but i need some help narrowing down articles because i'm getting way too much information.

hi there I need to find an article on homosexuality and mating what would be a good engine to search for that topic?

I am trying to find an american policy (previous or present) that targets Arab Americans / I am interested in the Hijab and my teacher said there is a lot on that subject but I am not finding anything that doesnt have to do with France / I am open to other things as well

I wanna find salient language characteristics of Scottish English. / But there are so many different sources, so I wanna know whether Scottish Gaelic is same as Scottish dialect language. / I have know idea what kind of phrase in searching boxes to find this info.

i am a [university] student and I am looking for a popular newspaper such as The Chicago Tribune regarding an article about "Race to the Top" How do I look for that? Hi do you know where I can find journals or articles about chemical ripening of plants? 
I need to find an article on statistics for my class and I wanted to find one about film. Also I'm trying to find information on Gods (particularly Athena and Poseidon and Zeus) in the Illiad and Odyssey

I was looking for something on homosexual adoption

Thank you. I'm not sure if I'm in the wrong research catalog but I'm having a difficult time finding any articles related Real Estate Sales (residential) and Home Staging (interior planning/placement of furnishings). It seems odd to me because it is a booming business in relation to Real Estate sales. / I'm in EBSCO in the Marketing area

I would like to compare Mp3 to a record player

Hello. I am writing a paper on hip hop's influence on inner city African American women and the differences between early rap and today's rap. I need 15 scholarly articles and I've found 13 so far, but am two short. Where would you suggest I look? I've tacked self esteem issues related to hip hop and adolescent's attitudes when it comes to hip hop, I even looked at eating disorders among AA women because of media's portrayals of hip hop in the media. Any suggestions?

I need to write on Leadership. I need to explore servant leadership / I need to anylyze its effectiveness in various circumstances, environments, stuations and provide examples

I need to explore leasdership across th globe especially as leaders relate to one another i need an article that relates brain activity or brain regions/functions that are related to the use of antidepressants in youth/ teens

how can i find online articles for a research paper about organic food? / Benefits of eating organic food / Why it is good for you and the enviornemnt

$\mathrm{Hi}$, if I want to find the topic, "divisions and unity within Islam" specifically from the 8 th to 12 th century, what is the best way to research?

i would like help searching for juornals and other sources on the war on drug

I'm looking for articles based off of my research topic on the educational differences between whites and blacks and how growing up in their environments has affected them, what would I type into the database to help me find the best article? / how it affects their future* sorry

my topic is cyber bullying

I am creating a training manual for my job at work as a Medicaid biller at a hospice agency. I need to find academic information on my "form" for my project, which is a training "procedures" manual and I am having a hard time finding anything academic. Any ideas on search words? I have been able to find "how to" guides on how to create a training manual, but am stumped on what I should be looking for as far as academic articles.

Hi. My research question is "How are data warehouses used by high school counselors?" this is the general topic however I do want to connect my findings to assert that data warehouses can be used to guide students to STEM careers

$\mathrm{Hi}$, I have a question concerning finding an area called "articles and market research reports"

I am looking for a good database to find sociology journals and academic sources for a project. I think my search was too narrow for a generic search on Ebscohost

i'm kind of confused as to what a public policy is and wanted to know if there's some way of confirming that one is such as the Clean Air act

Could you possibly help me narrow my search?? Topic: Compare and Contrast Latino family life and traditional american family life

I am writing a paper on the historical change of women in the homes

Hello, can some one help me? I am trying to find some resource regarding Nike, and its social responsibility. which category I need use? 
Hi Im looking for articles on how to become a phlebotomist or what it takes to become?? need help

Does [university] have access to a Hoover's type DB? / i am looking for data on local businesses

Hello, I am a sophomore at [university], and for my Spanish class we have to find an article in Spanish for an argumentative essay. I want to argue that undergraduate students should take at least two years of a modern language in order to graduate. I am having a difficult time finding an article in Spanish that discusses this issue. I am familiar with the [university] library webpage since I use it for all my research that I conduct, but I am having a difficult time finding an article for this assignment. I appreciate your help.

Hi. I am searching for Scholarly articles that can help me research whether children who are raised by a stay at home mom more likely to succeed than those raised by a working mom?

$\mathrm{Hi}$, i'm looking for a rich case study on schizophrenia and i was wondering what database would be the most resourceful.

How can I access documents ARCHIVE FOR REGISTERING DATA AND RECORDING TRENDS / $\mathrm{i}$ have a research paper / and the proff wants us to look for sources DOCUMENT ARCHIVE FOR REGISTERING DATA AND RECORDING TRENDS

Hello, I am trying to find statistics for crude oil and natural gas prices for the last 5 years. Can you point me in the right direction to find this data?

I am looking in particular for best practices on Religious Diversity in the workplace - so this popped up

where can I find scholarly information on how to create a checklist?

Hi. I'm looking for an article about Dubliners by James Joyce and psychoanalysis. I found something on JSTOR, but I'm not quite sure how to use that...can you please help?

I'm searching for sources on Grammar Instruction in ESL/TESL / I'm looking for an article in an encyclopedia or something that gives a broad description of the evolution of the field / that notes the seminal works and this areas progression

hello, i am looking for articles on frida kahlo and her use of symbolism, I was wondering what databases i could use to find such articles

Hi. I'm struggling to find sources related to creating a manual / user manual / instruction manual/ etc.

Hello! Would I find articles on Fad Dieting in Research Guides=> Health Sciences?

I am looking for articles on Adam Bede

Hi! For a political science course I am writing a paper on The Battle for Civil Unions and Gay Marriage and I am having trouble accessing journal articles

I'm looking for peer reviewed texts about the death of painting as an art form. can you help?

I was told I need to find information about how much annual revenue a company is bringing in / its for very small specific companies and I have no idea where to even start

Hello I need to know how to look up court cases

This article has to relate depression, youth, and brain regions

i was wondering how to llok for articles onthe history of Rebozos / on the origins of the Rebozo / in Mexico

I'm having issues searching for raw data in the "gay games". Specifically I'm looking at who funded the games. I've tried GenderWatch, ABI/Inform and Business Source Complete and none of them have the raw data I need. What would you suggest? 
Hello! I am looking for articles on child obesity. Would I find that under Research Guide: Health Sciences?

Hello i am trying to find an articles on Children who are just being sent to the next grade even tho they can not read. what would be the keyowrds for that?

Hi I am writing a concept analysis on the concept "guilt." I have found several uses of the word in psychology and criminal justice, but I am having a difficult time finding the use in Nursing. I have used Sage and Credo to perform the search, but have found very little. Is there a way to maximize the number of hits i get? thanks

I'm having trouble finding studies about pediatric tracheotomy care

My topic is private vs. public education

Hi there, Ineed help with a search please. I'm looking for articles discussing the connection between religion and domestic violence, specifically if religious organizations are helpful or not, what impact do they have on domestic violence prevention, etc. Also, my focus is on the South Asian culture. Thank you!

I am trying to locate books about capitalism that are physically at the [campus]. I can't make it [to another campus], but need 2-3 books for the weekend. This is a subject with many options and I was looking for a quick way to see what is available at the campus closest to me.

$i$ am writing a paper on the effect of media in influencing the society

gangs and drugs in [city] / okay what is my best bet for finding the most information on gangs and drugs and their evolution into the city / socio-economic in relation to status, class, environment and how that contributes to increasing gang violence in poverty stricken neighborhoods

hi i need to find an article on how physical exercise influences well-being can you help me?

I am trying to find recent articles in operations management published in newspapers, how or where do I search for them?

I have a research paper to do for a course on organizational culture. I am wondering how to make an appointment with a librarian. Not quite sure how to approach my topic: Discuss the basic principles of organizational culture and how it can be used to improved organizational performance AND explore how EITHER gender, race, social class or ethnicity come into play in organizational culture. Evaluate the positives and challenges of a diverse workforce within an organization. Not quite how to pull this into a cohesive paper.

My topic is the impact of higher education on the local community / I am looking for articles that discusses varies metrics used to measure the success or failure of their impact/involvement

PRISM surveillance program

Hello, I am trying to find a abnormal psychology case study from a psychology journal published within the last 5 years but am having a really hard time finding one with a rich background history. Do you have any tips?

University Library 2

hello there , my friend and I are looking for some books on how to open a small business.. and not sure if we are searching the right topics.. can you help us?

I am looking for articles on vertebrates and the circulatory system. But, I am having trouble finding reviews pertaining to this topic in PubMed.

Just curious, I'll be looking for articles concerning whether pre-school is a good investment or not, which databases would be the best to use?

I need to find an article on socio-cultural anthropology that is peer reviewed. Can you help me?

i was looking for video games affects on children 0-8yrs 
It seems I have to do this every semester. Hoping you can please assist me in getting to where I can search for peer reviewed journals. I am needing to find something on Addiction and brain based research

I am trying to find an article related to "evaluation and measurement in hrd"

Looking for journal articles on someone who has strong leadership skills in 2013

where can i find research articles on the [university] library website?

I am writing a literary analysis on The House on Mango Street for my english class/ and I am trying to find a literary critique article about the house on Mango Street but I can't find any good sources

Hi! I need to look up legal cases. Does the library have legal reference books like the Federal reporters and Regional reporters, etc.?

Hello, I am trying to find academic journals on Agenda-Setting Theory. Any suggestions on how I might go about finding them?

I need help trying to find articles about Polish school education (saturday school)

i need help finding information with cardiovascular disease

I need help finding a book about cervical cancer. help please?

$\mathrm{Hi}$, I need online articles / about Second language acquisition

this is my subject: age in second language acquisition

Hi I am doing a report on sorority and fraternities, are there any articles in your database? / the topic is very broad so anything will do

can you help me find a article on Uterine cancer?

I'm doing a research paper and my? Is should the school day be longer but I need to find history on it like school days in the 1950 and I cannot find anything

Oh, hello. I do need some help in trying to find the articles relating to my topic. I am a volunteer in the SitStayRead non profit organization that works with children to improve their literacy skills and to foster love in reading for these children that go to poverty schools. I've noticed that their literacy skills vary - some know very well how to read and write, while others are completely lost.

oh okay, well maybe you can help then. so im trying to look for articles that relate to my topic. my topic is: what is the difference between modern rock and their use of metaphors in thier lyrics.

hi, i'm working on a English paper which is a research [paper fo the final and I need some sources that talks about Teachers being ole models to their children and the role of counseling/support

Good morning, I am writing a review paper for [course number] on a journal article from 'Cognition' about the influence of depression on decision making. I need at least on hard copy source; I've found everything else I need on ERIC. Can you please point me to a section of the library that would have some books on psych texts on depression?

is there a book on Rosie the Rivter

what is the best database to find / cognitive benefits of bilingualism

I am having a hard time finding an article on learning another language being negative.

They agree it is a positive thing. Should I search on google?

Hello. I was wondering if you could help me find articles that talk about Political Ideologies and Palliative Care" and how social work plays a role in it

hello, how can I search for theoretical articles?

Hi I needed help finding articles on the U.S. lowering the drinking ag / age*

Hello, I was wondering if you might be able to help me find any books on the Arctic Glacier melting. And sea level rising?

I am looking for any articles that would be about global warming / but I cant find them can you help me? 
I need to search for articles on leadership and emotions. / What is the data base i need to get into

$\mathrm{Hi}$, I am doing a marketing plan for one of my classes and not long ago we had a presentation from a librarian that explained how to find profiles on companies but I forgot how to get to the site he showed us, is there any way you could help?

hello, is there anyway you may be able to help me find out more information about the arctic glacier melting?

what would you recommend using to do research on fast food meat processing besides websites?

Hi, Im having difficulty finding a book on why do leaves fall from trees

I am looking for some books with information on salicin, a natural anti-inflammatory... $\mathrm{Hi}$, I'd like some stats on how social media affects real social interactions

Are there any academic journals on the Chicano Movement?

quisiera consultar unas criticas sobre el beso de la mujer arana. Mepueden ayudar?

I am a student of [university] and I need to do a research on Market Securities, how can I look into the online data base for this subject

I am trying to get some information regarding fast food industry historical perspective

Hi. Can you please help me find books and or articles that explain how the Social aspect of [neighborhood] has changed. By social, I mean nightlife, community, food and culture. If this helps, this is for a sociology course.

im have trouble to find an article about (developing a curriculum for math subject in [city] public school). I know how to search articles, but the problem when I write the words it comes lots of articles and not connect to my subject. 


\section{APPENDIX B. Database Recommendations}

UL1 (50 different recommendations): Academic Search Complete (13), Business Source Complete (7), PsycInfo/PsycArticles (6), Chicago Tribune (4), CINAHL (4), ABI/ Inform (3), JSTOR (3), Sociological Abstracts (3), WorldCat Local (default discovery layer) (3), Art Full Text (2), Chicago Sun-Times (2), CQ Researcher (2), Education Research Complete (2), Environment Complete (2), ERIC (2), LexisNexis (2), Linguistics and Language Behavior Abstracts (2), MLA International Bibliography (2), SAGE Knowledge (2), Wall Street Journal (2), ATLA, Biological \& Agricultural Index, Biological Abstracts, BizMiner, Communication \& Mass Media Complete, Communication Abstracts, Gale Directory of Publications and Broadcast Media, Genderwatch, Health Source Academic, Health Source Nursing/Academic, Hispanic Periodicals, Historical Abstracts, International Encyclopedia of Social and Behavioral Sciences, Lexis/Nexis, Music Index, New York Times, Occupational Outlook Handbook, Oxford English Dictionary, PAIS, ProQuest Political Science, ProQuest Social Science Journals, ReferenceUSA, RILM, ScienceDirect, Social Sciences Abstracts, Women Studies Abstracts, Women's Studies International, www.guidestar.org, www.usgs.gov, "top three databases" on Education guide

UL2 (13 different recommendations): Academic Search Complete/Premier (default on home page) (13), Business Source Elite (2), ERIC (2), JSTOR (2), library catalog (2), PsycInfo (2), EBSCO, Google Scholar, MLA International Bibliography, NetAdvantage, openjurist.org, PubMed, Social Services Abstracts

\section{Notes}

1. Catherine Sheldrick Ross and Patricia Dewdney, "Negative Closure: Strategies and CounterStrategies in the Reference Transaction," Reference \& User Services Quarterly 38, no. 2 (1998): 151-63.

2. Anna Burke, personal e-mail, "Data on Spread of LibGuide Use," May 18, 2015.

3. Anita R. Schiller, "Reference Service: Instruction or Information," Library Quarterly 35, no. 1 (1965): 52-60; Charles R. McClure, "A Reference Theory of Specific Information Retrieval," RQ 13, no. 3 (1974): 207-12; Constance Miller and James Rettig, "Reference Obsolecence," $R Q 25$, no. 1 (1985): 52-58; Bill Katz, "Long Live Old Reference Services and New Technologies," Library Trends 50, no. 2 (2001): 263-85.

4. Susan E. Beck and Nancy B. Turner, "On the Fly BI: Reaching and Teaching from the Reference Desk," Reference Librarian 72 (2001): 83-96; James K. Elmborg, "Teaching at the Desk: Toward a Reference Pedagogy," portal: Libraries and the Academy 2, no. 3 (2002): 455-64, http://www. columbia.edu/cu/libraries/inside/units/bibcontrol/osmc/elmborg.pdf; Susan Avery and David Ward, "Reference Is My Classroom: Setting Instructional Goals for Academic Library Reference Services," Internet Reference Services Quarterly 15, no. 1 (2010): 35-51; Reference \& User Services Association, "Guidelines for Behavioral Performance of Reference and Information Service Providers," American Library Association (May 28, 2013), available online at www.ala.org/rusa/resources/ guidelines/guidelinesbehavioral [accessed 20 September 2017]; Association of College \& Research Libraries, "Standards for Libraries in Higher Education," American Library Association (Oct. 2011), available online at www.ala.org/acrl/standards/standardslibraries [accessed 20 September 2017].

5. Association of College \& Research Libraries, "Information Literacy Competency Standards for Higher Education," American Library Association (2000), available online at www.ala.org/acrl/ standards/informationliteracycompetency [accessed 20 September 2017].

6. Association of College \& Research Libraries, "Standards for Libraries in Higher Education."

7. Reference \& User Services Association, "Guidelines for Behavioral Performance of Reference and Information Service Providers."

8. Ross and Dewdney, "Negative Closure," 161.

9. Ibid., 153.

10. Patricia E. Johnston, "Digital Reference as an Instructional Tool: Just in Time and Just Enough," Searcher 11, no. 3 (Mar. 2003): 31.

11. Christina M. Desai and Stephanie J. Graves, "Instruction via Instant Messaging Reference: What's Happening?" Electronic Library 24, no. 2 (Mar. 2006): 185, doi:10.1108/02640470610660369.

12. Christina M. Desai and Stephanie J. Graves, "Cyberspace or Face-to-Face: The Teachable 
Moment and Changing Reference Mediums," Reference \& User Services Quarterly 47, no. 3 (2008): 250.

13. Avery and Ward, "Reference Is My Classroom," 44.

14. Miriam L. Matteson, Jennifer Salamon, and Lindy Brewster, "A Systematic Review of Research on Live Chat Service," Reference \& User Services Quarterly 51, no. 2 (December 2011): 185, doi:10.5860/rusq.51n2.172.

15. Avery and Ward, "Reference Is My Classroom," 41.

16. Johnston, "Digital Reference as an Instructional Tool"; Lesley M. Moyo, "Virtual Reference Services and Instruction: An Assessment," Reference Librarian 46, no. 95/96 (Sept. 2006): 213-30.

17. Megan Oakleaf and Amy VanScoy, "Instructional Strategies for Digital Reference," Reference \& User Services Quarterly 49, no. 4 (June 2010): 385, doi:10.5860/rusq.49n4.380.

18. Beck and Turner, "On the Fly BI," 90.

19. Ruth L. Baker, "Designing LibGuides as Instructional Tools for Critical Thinking and Effective Online Learning," Journal of Library \& Information Services in Distance Learning 8, no. 3/4 (Oct. 2014): 107-17, doi:10.1080/1533290X.2014.944423.

20. Bradley Brazzeal, "Research Guides as Library Instruction Tools," Reference Services Review 34, no. 3 (2006): 358-67.

21. Jonathan Miner and Ross Alexander, "LibGuides in Political Science: Improving Student Access, Research, and Information Literacy," Journal of Information Literacy 4, no. 1 (June 2010): $40-54$.

22. Diane May and H. Vernon Leighton, “Using a Library-Based Course Page to Improve Research Skills in an Undergraduate International Business Law Course," Journal of Legal Studies Education 30, no. 2 (2013): 295-319; H. Vernon Leighton and Diane May, "The Library Course Page and Instruction: Perceived Helpfulness and Use among Students," Internet Reference Services Quarterly 18 (2013): 127-38.

23. Karen M. Neves and Sarah Jane Dooley, "Using LibGuides to Offer Library Service to Undergraduate Medical Students Based on the Case-Oriented Problem Solving Curriculum Model," Journal of the Medical Library Association 99, no. 1 (Jan. 2011): 94-97.

24. Kimberly Pendell and Annie Armstrong, "Psychology Guides and Information Literacy: The Current Landscape and a Proposed Framework for Standards-Based Development," Reference Services Review 42, no. 2 (June 2014): 293-304, doi:10.1108/RSR-10-2013-0052.

25. Mira Foster et al., "Marketing Research Guides: An Online Experiment with LibGuides," Journal of Library Administration 50 (2010): 602-16.

26. Ryan S. Rafferty, "The Impact of Library Instruction: Do First-Year Medical Students Use Library Resources Specifically Highlighted during Instructional Sessions?" Journal of the Medical Library Association 101, no. 3 (July 2013): 213-17, doi:10.3163/1536-5050.101.3.011.

27. Pendell and Armstrong, "Psychology Guides and Information Literacy."

28. Paula R. Dempsey, "'Are You a Computer?': Opening Exchanges in Virtual Reference Shape the Potential for Teaching," College \& Research Libraries 77, no. 4 (July 2016): 455-68, doi:10.5860/ crl.77.4.455.

29. Ken W. Parry, "Constant Comparison," in Encyclopedia of Social Science Research Methods (Thousand Oaks, Calif.: SAGE, 2004), 181-82.

30. Transcripts with a subject research question went in this category even if they also included other question types (such as directional, known item, or material type questions).

31. Both libraries used the LibraryH3lp system for live chat, which does not support cobrowsing. If a librarian provided a link, clicking on it took the student out of the chat. There was no way to know whether the student followed the link or examined the resource unless it came up in the transcript.

32. Association of College \& Research Libraries, "Framework for Information Literacy for Higher Education," American Library Association (Feb. 2, 2015), available online at www.ala.org/ acrl/standards/ilframework [accessed 20 September 2017].

33. Pendell and Armstrong, "Psychology Guides and Information Literacy."

34. Colin Elman, Diana Kapiszewski, and Lorena Vinuela, "Qualitative Data Archiving: Rewards and Challenges," Political Science and Politics 43, no. 1 (Jan. 2010): 23-27, doi:10.1017/ S104909651099077X. 